\title{
The effect of cavity restoration variables on odontoblast cell numbers and dental repair
}

\author{
I. About ${ }^{\mathrm{a}}$, P.E. Murray ${ }^{\mathrm{b}, *}$, J.-C. Franquin $^{\mathrm{a}}$, M. Remusat ${ }^{\mathrm{a}}$, A.J. Smith ${ }^{\mathrm{b}}$ \\ ${ }^{a}$ Faculté d'Odontologie, Université de la Méditeranée, Laboratoire, I.M.E.B, 27 Bvd Jean-Moulin, 13385 Marseille, Cedex 5, France \\ ${ }^{\mathrm{b}}$ OralBiology, 7th Floor, SchoolofDentistry, The University of Birmingham, StChad's Queensway, Birmingham, B46NN, UK
}

\begin{abstract}
Objectives: Dentinal repair following cavity restoration is dependent on several parameters including the numbers of surviving odontoblasts. The purpose of this study was to examine the effects of cavity cutting and restoration treatments on post-operative odontoblast numbers.

Methods: 353 Standardised non-exposed rectangular Class V cavities, were cut into the buccal dentin of intact 1st or 2nd premolar teeth of 165 patients, aged between nine and 25 years of age. Composite cavity restorations with various etching treatments were compared with resin-modified glass ionomer cements, enamel bonding resins, as well as polycarboxylate, calcium hydroxide, and zinc oxide eugenol materials. Following tooth extraction (20-381 days) for orthodontic reasons, the area of the reactionary dentine and the area of the odontoblasts was measured histomorphometrically.

Results: Odontoblast numbers and dentine repair activity were found to be influenced more by cavity restoration variables, than the choice of cavity filling materials or patient factors. The most important cavity preparation variable was the cavity remaining dentine thickness (RDT); below $0.25 \mathrm{~mm}$ the numbers of odontoblasts decreased by $23 \%$, and minimal reactionary dentine repair was observed.

Conclusions: Odontoblast injury increased as the cavity RDT decreased. In rank order of maintaining odontoblast numbers beneath restored cavities with a RDT below $0.5 \mathrm{~mm}$, and using calcium hydroxide for comparison; calcium hydroxide (100\%), polycarboxylate $(82.4 \%)$, zinc oxide eugenol (81.3\%), composite $(75.5 \%)$, enamel bonding resin $(49.5 \%)$ and RMGIC (42.8\%). The vitality and dentine repair capacity of the pulp is dependent on odontoblast survival. Variations in the extent of odontoblast injury caused during operative procedures, may be the major underlying reason for the success or failure of restorative treatments. C) 2001 Elsevier Science Ltd. All rights reserved.
\end{abstract}

Keywords: Tertiary dentinogenesis; Cavity restoration; Pulp; Odontoblast; Dentin thickness

\section{Introduction}

The successful resolution of restorative treatments is dependent in harnessing and utilising the natural repair responses of the pulpal cell populations, especially the odontoblasts [1]. The other pulpal cell populations which occupy the subodontoblast layer and the pulp core, are important in supporting dentinogenesis, but do not appear to play a direct role in the secretion of dentine matrix [2]. The maintenance and repair of dentine is accomplished by the secretory activity of odontoblast cells. With their peripheral location in the dental pulp and their cellular process transversing dentine, the odontoblasts have been demon- strated to detect and respond to dentine injury following caries and restorative dental procedures [3-8]. Odontoblasts are highly differentiated post-mitotic cells which regulate dentine synthesis, secretion and mineralisation throughout life. The rate of dentine secretion by odontoblasts has been observed to vary according to the chronology and circumstances of its secretion. Because of this, dentine secretion can be classified as either primary, secondary or tertiary in origin. In humans, primary dentine is secreted at a rate of approximately 4 microns per day during tooth development, until the completion of root formation [9]. Thereafter, physiological secondary dentine is laid down at a reducing rate of approximately 0.5 microns per day, along the pulpdentine border throughout life [10,11]. In the event of primary and secondary dentine injury, the intrinsic capacity of the dental pulp to repair lost or damaged dentine, and to increase the barrier between itself and the injurious stimuli, 
Table 1

Experimental groups for study of restoration materials and number of cavities examined

\begin{tabular}{rlll}
\hline No. & Restoration type & Cavity restoration material & Cavities \\
\hline 1 & Adhesive systems & Scotchbond + Silux & 41 \\
2 & Adhesive systems & EDTA etching + Scotchbond + & 40 \\
& & Silux & 41 \\
3 & Adhesive systems & Phosphoric acid etching + & \\
& & Scotchbond + Silux & 33 \\
4 & Adhesive systems & Phosphoric acid & 38 \\
& & etching + Scotchprep + Silux & 33 \\
5 & Adhesive systems & Gluma Bond + Lumifor & 31 \\
6 & Adhesive systems & Syntac + Heliomolar & 12 \\
7 & Resin ionomer & Vitremer & 44 \\
8 & Resin ionomer liner & Vitrabond & 11 \\
9 & Enamel bonding resin & XR Bond & 19 \\
10 & Polycarboxylate & Acid base & 10 \\
11 & Calcium hydroxide & Dycal & \\
12 & Zinc oxide eugenol & Zinc oxide eugenol/Intermediate & restoration material
\end{tabular}

is dependent on the vitality of the odontoblast cell layer to secrete tertiary dentine. The process of tertiary dentine secretion can be classified as being reactionary in origin, depending on the severity of the initiating response and the conditions under which the dentine matrix was secreted [12-14]. The secretion of reactionary dentine is the main postoperative odontoblast repair response to an unexposed cavity restoration which has been carefully cut into the dentine of a tooth [15].

The rate of reactionary dentine secretion has been estimated to be three times that of secondary dentine [16] in response to environmental and accidental events such as caries, attrition, abrasion, erosion and trauma. However, in many cases greater traumatic dentine injury is caused by the surgical techniques and materials used to restore the tooth structure following these events. Sources of injury associated with restorative procedures have included conditioning of the dentine cavity wall [17], presence of bacteria [1820], method of placement of the restorative material [21,22], desiccation [23], pulpal inflammation related to remaining dentin thickness (RDT) [24,25], chemical irritants [26], restoration material toxicity [27] and restoration material temperature $[28,29]$. Odontoblast survival is a multifactorial process and all of the above factors may individually or cumulatively play a role in the degree of injury to the odontoblasts. Limiting odontoblast injury may be advantageous to avoid recurring postoperative pulp complications and endodontic therapy. The emphasis of this study was to assess odontoblast survival and their secretory activity following placement of a variety of cavity restorative materials, and parameters of cavity preparation, because these two factors appear to be among the most controllable and avoidable sources of injury. Evidence is accumulating to show that the degree of dentinal repair is proportional to the magnitude of the dentine injury, as well as the numbers of the odontoblast cells existing beneath the site of dentine injury [1]. However, clinical information on odontoblast numbers and activity in relation to different restorative materials, cavity etching treatments and cavity cutting variables, such as RDT of cavity preparations is limited. These factors are still of major concern in restorative and prosthodontic dentistry, because according to many longitudinal investigations, there is still a high rate of vital teeth exhibiting typical signs of endodontic complications following dental restoration [30]. Consequently, the purpose of this study was to examine odontoblast survival and reactionary dentine secretion in 353 cavities restored with calcium hydroxide, zinc oxide eugenol (ZOE), composites, and resin-modified glass ionomer cements (RMGIC).

\section{Materials and methods}

165 healthy patients $(63.4 \%$ female; $36.6 \%$ male) with noncarious intact first or second maxillary or mandibular premolars, had class V cavities prepared in 353 teeth, which were scheduled for extraction for orthodontic reasons at the Marseille Hospital dental care centres. The patients were between nine and 25 years of age, and proper patient/ parental informed consent was obtained. After a post-operative interval of 20-381 days, the teeth were extracted using a local anaesthetic. The standardised methods and procedures used in this study have been described elsewhere [1]. Briefly, class $\mathrm{V}$ cavity preparations were placed in the buccal surface of teeth, $1 \mathrm{~mm}$ above the level of the cementoenamel junction. Cavity preparations were cut into the dentine using the least possible pressure at a drill speed of $400,000 \mathrm{rpm}$ with water spray coolant. Cavity RDT ranged between 0.008 and $2.578 \mathrm{~mm}$ with a mean of $0.833 \mathrm{~mm}$, and axial floor widths between 1.012 and $3.392 \mathrm{~mm}$ with a mean of $1.943 \mathrm{~mm}$.

Teeth were assigned to 12 experimental groups (1-12) for restoration (Table 1). All the products were used strictly according to their manufacturers' instructions, except for Scotchbond adhesive (3M Dental St Paul, MN, USA) restorations, which included a no etching treatment (group 1) and an alternative etching treatment using $17 \%$ ethylene diamine tetra acetic acid (EDTA) (Dentin conditioner, 3M Dental Products, St Paul, MN, USA) to remove smear layer (group 2). Group 3 followed the manufacturer's recommended instructions for acid etching cavity walls using 37\% phosphoric acid gel. In addition, Scotchprep (3M Dental Products, St Paul, MN, USA) (group 4) was used to restore 33 teeth, using the same procedure as Scotchbond group 2. All the Scotchbond adhesive restorations (groups 1-4) were filled with a light curing composite resin (Silux, 3M Dental St Paul, MN, USA), according to the manufacturer's recommendations. Group 5 involved restoring 38 cavities with Gluma (Bayer Dental, Leverkusen, Germany) before filling with Lumifor resin (Bayer Dental, Leverkusen, Germany). In group 6 Syntac (Vicadent, Schann, Liechtenstein) was used to restore 33 cavity 
Table 2

Hierarchy of variables in rank order of their effect on odontoblast cell numbers beneath cavity restorations

\begin{tabular}{ll}
\hline Variable & $\begin{array}{l}\text { Cavity odontoblasts } \\
\text { per unit area } \\
\text { (ANOVA) } P \text { value) }\end{array}$ \\
\hline Cavity remaining dentine thickness & 0.0001 \\
Cavity wall depth & 0.0001 \\
Cavity wall area & 0.0001 \\
Pulpal inflammation related to RDT & 0.0001 \\
Type of restoration material & 0.0001 \\
Total cavity surface area & 0.0013 \\
Etching (cavity conditioning) & 0.0044 \\
Cavity volume & 0.0069 \\
Reactionary dentine area & 0.0172 \\
Sex of patient & 0.2063 \\
Cavity floor width & 0.2211 \\
Patient age & 0.2226 \\
Bacteria within restorations & 0.3892 \\
Cavity floor area & 0.6794 \\
Bacteria in cut dentinal tubules & 0.5677 \\
Time elapsed since operative procedures & 0.7557 \\
\hline
\end{tabular}

preparations with Heliomolar resin (Vivdent, Schann, Liechtenstein). Cavities (groups 7-9) were prepared and conditioned with $37 \%$ phosphoric acid gel before restoration with resin-modified glass ionomer cements; Vitremer, (3M Dental St Paul, MN, USA), Vitrabond, (3M Dental St. Paul, MN, USA), and enamel bonding resin; XR Bond, (Kerr, Romulus, MI, USA). Cavities (groups 10 and 11) were lined with either a polycarboxylate cement, or calcium hydroxide cement (Dycal, Kerr, Romulus, MI, USA). Cavities (Group 12) were lined with ZOE (Kalzinol, Dentsply, Zurich, Switzerland) or a reinforced ZOE product (Intermediate restoration material, De Trey Dentsply, Zurich, Switzerland). This study represents data collected over several years. Manufacturers frequently change the formulation of their products, and so to ensure that the data presented in this paper remain relevant in the years ahead, the emphasis has been to compare types of restoration product and placement methods, rather than individual products. Extracted teeth were prepared for light microscopy and a histomorphometric analysis was conducted, as described previously [1]. Briefly, 5 micron tooth sections were stained with haematoxylin and eosin, the area of reactionary dentin was estimated histomorphometrically at $\times 10$ magnification using a grid eyepiece graticule, and the cavity RDT was also estimated. Morphologically intact odontoblasts were counted beneath the cavity preparations per $2112 \mu \mathrm{m}^{2}$ of pulpal unit area. Pulpal inflammatory responses were categorised as either slight, moderate or severe on the basis of FDI standards and published criteria [31,32].

In addition to other distinguishable pathological features, essentially a severe response indicated the complete disintegration of the odontoblasts, a moderate response indicated a reduction of the odontoblasts, and a slight inflammatory response indicated that the odontoblast layer appeared normal. Bacterial contamination of the restorations, or the underlying dentinal tubules, was assessed using the BrownBrenn procedure [31] for the presence of Gram positive and negative bacteria. The raw numerical data were examined using Analysis of Variance (StatView software, SAS Inc.).

\section{Results}

\subsection{Odontoblast numbers beneath cavities}

The preservation of a single layer of odontoblasts could be observed beneath the cavity restorations; however, the numbers of odontoblasts were observed to be influenced to varying degrees by cavity preparation, the type of restoration and patient factor variables. These variables are ranked together in a hierarchy of importance to odontoblast numbers in Table 2.

\subsection{Area of reactionary dentine secreted}

Secretion of a tertiary dentine matrix by odontoblasts was observed beneath $52.7 \%$ of cavity restorations. In all cases, a histomorphological evaluation of the tertiary dentine matrix, revealed a tubular continuity between the secondary dentin matrix and the pre-existing odontoblasts. These observations classify the secreted dentin matrix as being reactionary in origin [34]. The area of reactionary dentine was found to be influenced by the numbers of odontoblasts beneath the site of cavity preparation (Table 2 ). The area of reactionary dentine was found to increase, with numbers of odontoblasts, suggesting that the repair of dentine matrix is probably dependent on maintaining odontoblast survival following operative procedures.

\subsection{Cavity preparation effects on odontoblast numbers}

The RDT of cavity restorations appeared to have a greater influence on the underlying odontoblast numbers, than any of the other cavity restoration variables (Table 2 ). The odontoblast numbers appeared to decrease as the cavity remaining dentine thickness was reduced, with the most severe reductions in numbers being seen beneath cavities with the least RDT (Fig. 1). The mean number of odontoblasts beneath cavity preparations with a RDT below $0.25 \mathrm{~mm}$, was found to be approximately $23 \%$ less than that with a RDT between 0.25 and $0.5 \mathrm{~mm}$. The relationships between odontoblast numbers and the cavity wall depth, cavity wall area, total cavity surface area, the cavity volume, all followed a similar pattern to the RDT. The increasing scale of these variables, caused by an increase in the extent of operative procedures and increased cavity size, had a tendency to reduce the numbers of underlying odontoblasts (Table 2). The sizes of the cavity floor width and cavity floor area, did not appear to appreciably influence odontoblast 


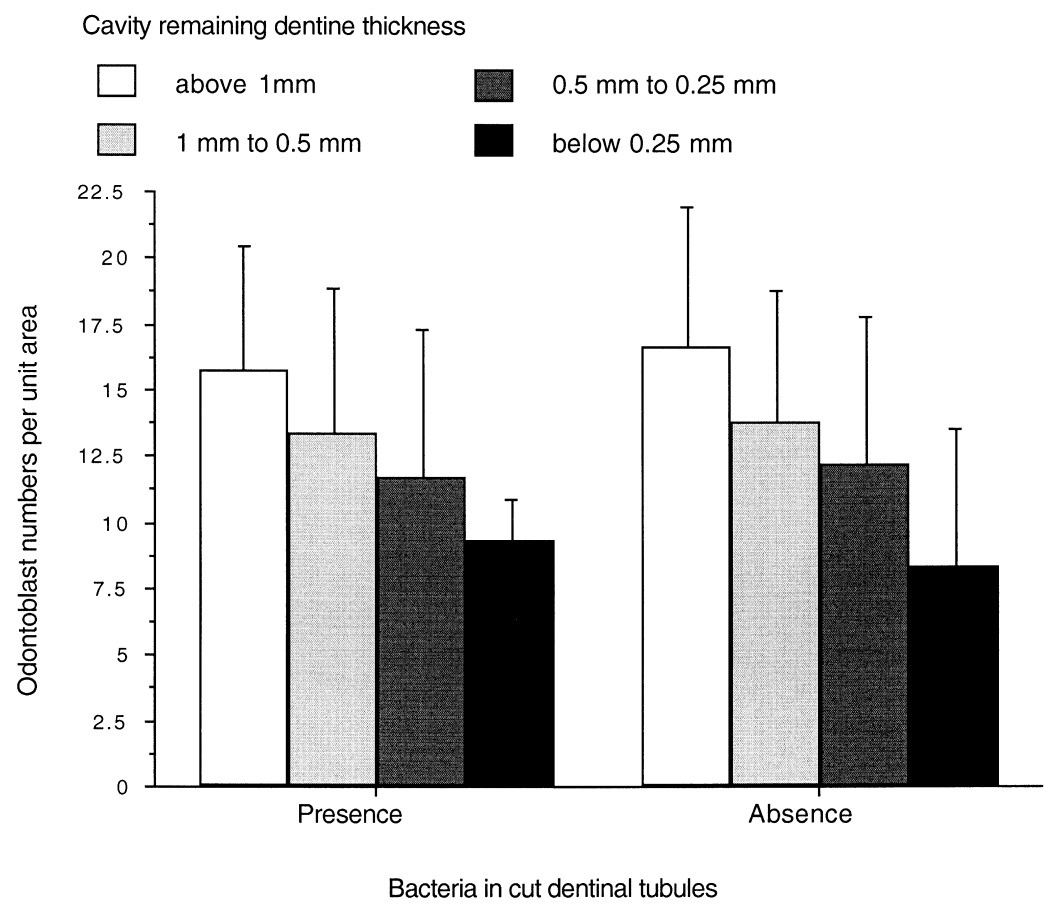

Fig. 1. Odontoblast numbers beneath cavity restorations of various remaining dentine thicknesses.

numbers when measured independently of the RDT (Table 2).

\subsection{Evaluation of cavity restoration materials}

The choice of type of cavity restoration material, appeared to be a critical factor in maintaining odontoblast numbers beneath cavity restorations, as the odontoblast numbers appeared to be more sensitive to the effects of some materials, than others. The sensitivity of the odontoblast numbers to different materials, was particularly noticeable when the cavity RDT was below $0.5 \mathrm{~mm}$ (Fig. 2). In rank order of maintaining odontoblast numbers beneath restored cavities with a RDT below $0.5 \mathrm{~mm}$, and using calcium hydroxide for comparison; calcium hydroxide (100\%), polycarboxylate $(82.4 \%)$, ZOE $(81.3 \%)$, composite $(75.5 \%)$, enamel bonding resin $(49.5 \%)$ and RMGIC $(42.8 \%)$.

\subsection{Etching}

Etching of the instrumented cavity walls was found to influence the numbers of odontoblasts beneath cavity preparations relative to unetched preparations (Table 2), particularly when the RDT was below $0.5 \mathrm{~mm}$ (Fig. 3). The mean numbers of odontoblasts beneath cavities with a RDT below $0.5 \mathrm{~mm}$, following phosphoric acid etching, was found to be approximately $13.8 \%$ less than the mean numbers following EDTA etching. The mean odontoblast numbers beneath unetched cavities, was reduced by $21.7 \%$ in comparison with EDTA etched cavities, under similar circumstances.

\subsection{Bacteria}

The Brown-Brenn procedure [33] identified bacteria in $12.12 \%$ of all the restored cavities, and only small to medium numbers of bacteria were identified within cut dentin tubules. Although the presence of bacteria within cut dentinal tubules and cavity preparations, appeared to reduce the numbers of odontoblasts slightly (Fig. 1), the influence of bacterial infiltration was not found to be an important factor influencing odontoblast numbers (Table 2).

\subsection{Pulpal inflammatory activity related to cavity remaining dentine thickness}

The lack of severity of pulpal inflammatory activity, was found to be important in maintaining odontoblast numbers (Table 2). Optimum odontoblast numbers were maintained beneath cavity restorations with a RDT above $0.5 \mathrm{~mm}$ with slight inflammatory activity; conversely, the most marked reduction in numbers was observed beneath cavities exhibiting severe inflammatory activity with a RDT below $0.5 \mathrm{~mm}$ (Fig. 4).

\subsection{Variables with an insignificant correlation to the number of odontoblasts}

The following variables were found to have an insignificant correlation with the number of odontoblasts per unit area: sex of patient; cavity floor width; patient age; bacteria within restorations; area of cavity floor; bacteria within cut dentinal tubules; and time elapsed since operative procedures (Table 2). 


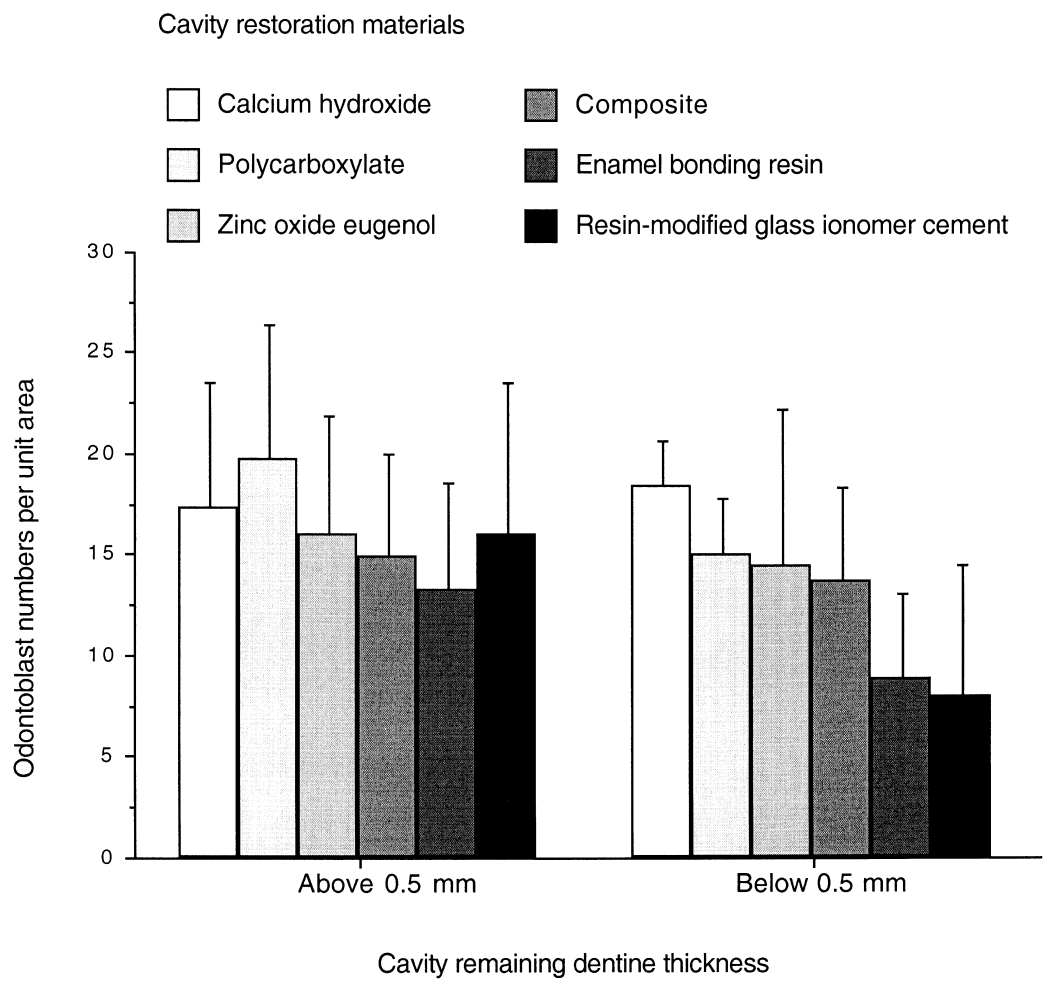

Fig. 2. Odontoblast numbers beneath cavities restored with different restoration materials.

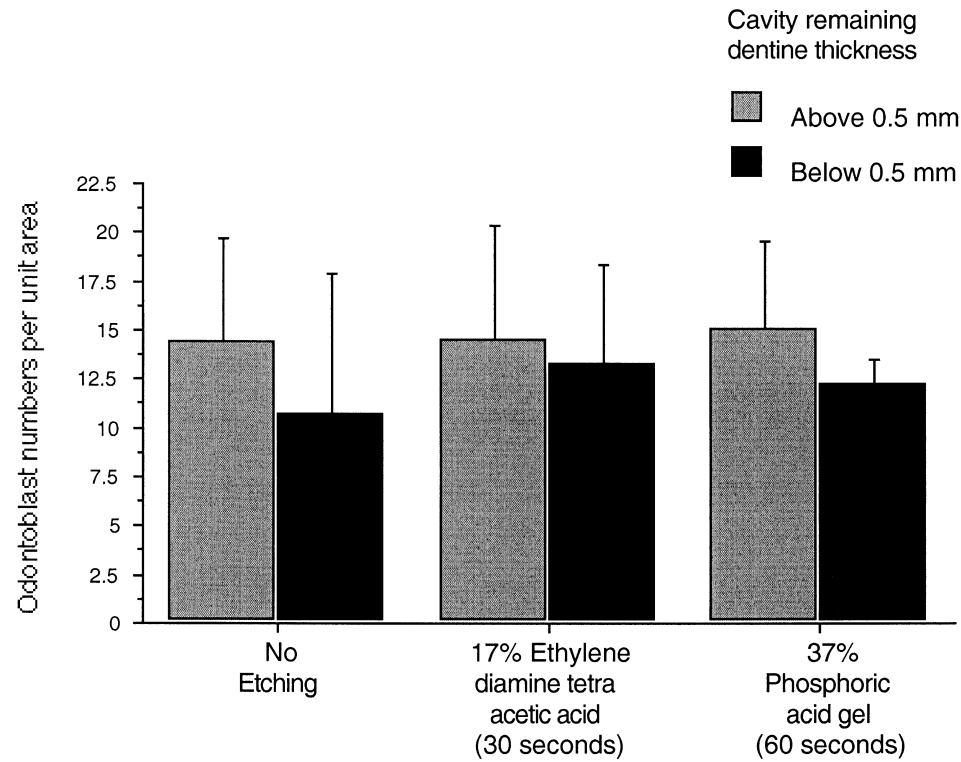

Etching of restoration cavity walls

Fig. 3. Odontoblast numbers beneath composite restorations following cavity etching treatments.

\subsection{Controls}

Because of the powerful effect that the cavity RDT has on odontoblast numbers, it is essential to remove the possibility of a mismatch of RDTs between each of the restoration variables. The cavity RDTs were measured and compared with each other using ANOVA statistics. No significant differences were observed at the $P=0.05$ significance level for bacteria in tubules beneath restoration $(P=0.688)$, or on cavity walls $(P=0.721)$, etching $(P=0.281)$, pulpal inflammation related to RDT $(P=0.156)$, restoration materials $(P=0.142)$. 


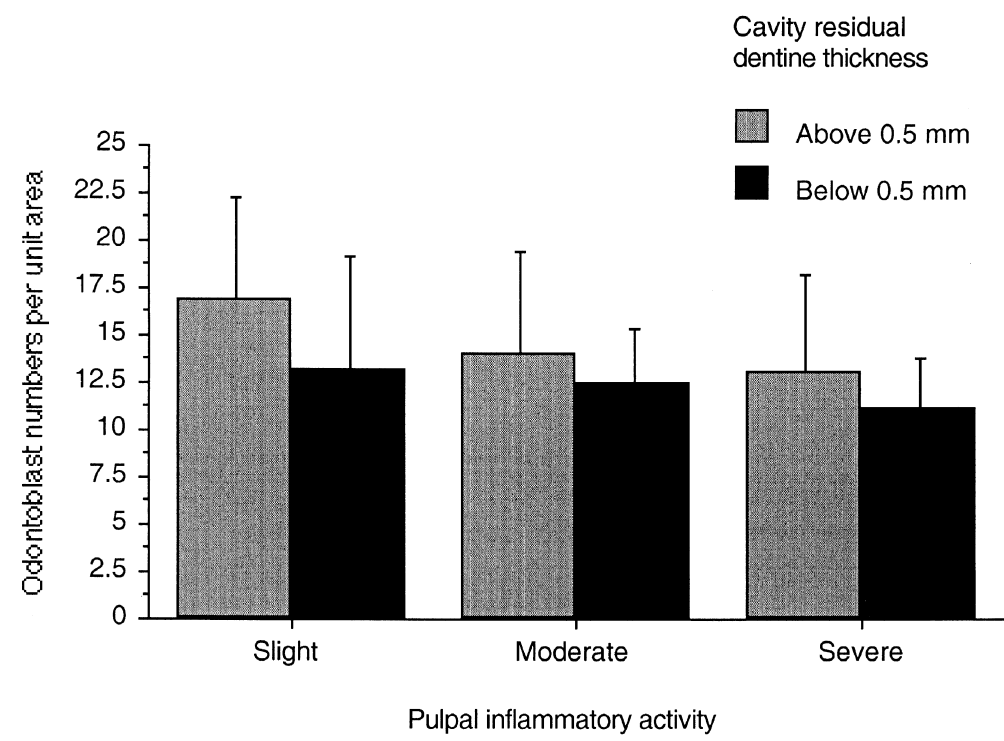

Fig. 4. Odontoblast numbers and pulpal inflammatory activity beneath cavity preparations of various dentine thicknesses.

\section{Discussion}

The most common method of evaluating pulp tissue reactions to injury is by the qualitative assessment of pulp tissue alterations; however, these methods can be subjective [35]. A further problem with these methods, is that although different types of cell death events are easily distinguishable [36], and molecular markers are available for detecting cell death responses [37], human studies can be limited by the need for chronological information on the post-treatment tissue events. Consequently, this explains the need to examine a relatively large sample of 353 teeth, extracted over a great length of time; 20-381 days post-operatively. In comparison to qualitative approaches to examine pulpal activity, our morphometric analysis of odontoblast cell numbers has proved, in common with previous morphometric studies $[35,38]$ to be able to provide a relatively uncomplicated method for examining a number of variables of interest. The ANOVA methods used in this study have shown the potential to provide information about the number of odontoblasts per unit area, in response to the variables of cavity preparation, restoration as well as patient factors.

The relationship between odontoblast numbers and the cavity wall depth, cavity wall area, total cavity surface area, and cavity volume all followed a similar pattern to the RDT. The increasing scale of these variables, caused by an increase in the extent of operative procedures and increased cavity size, had a tendency to reduce the numbers of underlying odontoblasts (Fig. 1). The reduction in odontoblast numbers with a decreasing cavity RDT concurs with previous reports [20,39-42]. The cause of this reduction may be the increasing diffusion of potentially injurious cytotoxins from restoration materials in a pulpward direction $[43,44]$. In support of this hypothesis, the size of the cavity floor width, and cavity floor area, appeared to have little influence on odontoblast numbers (Table 2). Nevertheless, consideration should also be given to the injurious effect of frictional heat generated during cavity cutting [45] and the production of injurious audible and ultrasonic vibrations [46]. Limited information is available about ultrasonic vibrations, but the amount of intrapulpal heat generated during cavity preparation and restoration is determined by the drill rotation speed [47-50], size, type and shape of the cutting instrument [51,52], length of the time the instrument is in contact with the dentine [53], the amount of pressure exerted on the hand piece [54,55], cutting technique [56] and the use of coolants [57-59]. Consequently, all these variables have the ability to increase the severity of injury caused by cavity preparation on the underlying pulp tissue.

The etching of cut dentine cavity walls with acids to condition the smear layer prior to filling with composites has been the subject of much controversy, particularly in regard to the survival of odontoblasts and other cell populations. EDTA is cytotoxic to tissues [60], and can render dentine more permeable, facilitating the passage of bacteria or cytotoxic chemicals towards the pulp [61]. Nevertheless, EDTA cavity etching was not observed to cause any great reduction in the numbers of odontoblasts. Phosphoric acid etching appeared to cause a marginally greater reduction in odontoblast cell numbers than EDTA etching, when the cavity RDT was below $0.5 \mathrm{~mm}$ (Fig. 1). Despite all this evidence on the possible injurious effects of acid etching, the most injurious treatment was found to be the restoration of cavities with an intact smear layer. The exact reason why this treatment was the most injurious to underlying odontoblasts is not known, but it may be related to the fact that unetched cavity restorations were probably not sealed adequately or that the restorative material itself dissolved the smear layer. Inadequate cavity sealing has been 


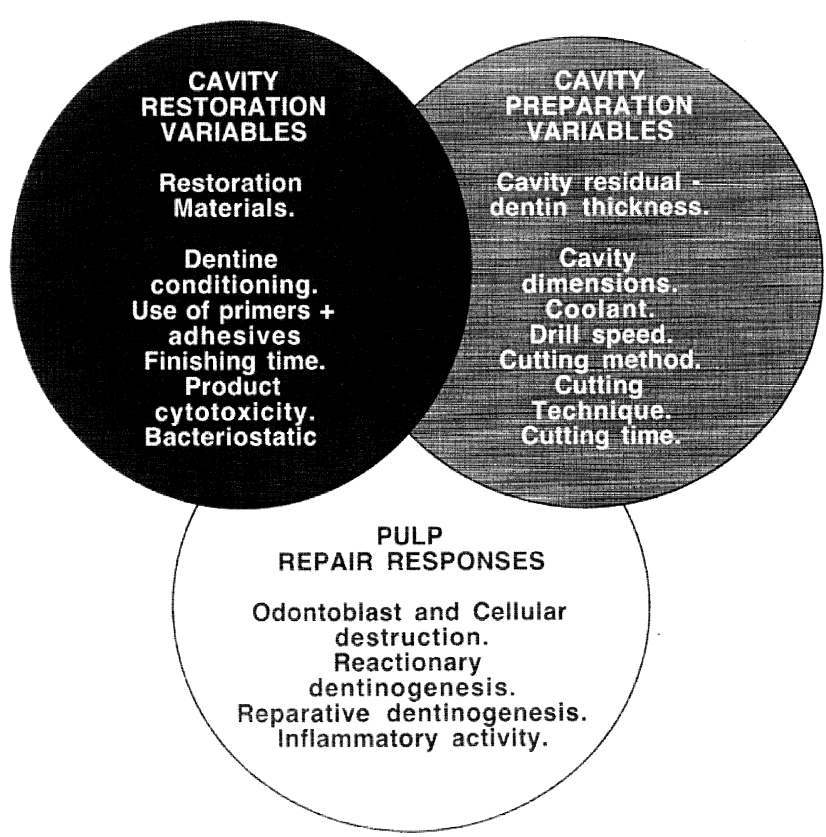

Fig. 5. Possible sources of odontoblast injury which may affect dental repair activity.

suggested to cause an increased risk of microleakage, pulpal inflammation and complications [62-64]. The acid etching of cavity preparations has also been noted to be advantageous for the longevity and adherence of restorations $[65,66]$. Consequently, the placing of composite restorations in unetched cavity preparations cannot be recommended.

The presence of bacteria in cavity restorations had little influence on the odontoblasts beneath cavity preparations, in comparison with restorations in which no bacteria were detected. The lack of importance of this variable may be explained by our observations of only small or moderate numbers of bacteria within the cavity restorations. In cases where the presence of bacteria is greater, some reductions in odontoblast survival may be expected. Although the presence of bacteria had little influence on odontoblast numbers, it has been established that the inflammatory response to the presence of bacteria in cavity restorations can be injurious to pulp tissue [18,24]. This is in agreement with our findings, where the optimum numbers of odontoblasts were maintained when inflammatory activity was slight_or least severe (Fig. 4). Severe inflammatory activity will injure pulpal cell populations, reducing pulpal vitality, and in the most severe cases obliterate the whole tooth pulp. Consequently, the minimisation of severe pulpal inflammatory activity can benefit the success of restorative treatments, and this requires pulp protection from microleakage [24,27].

In addition to cavity etching, the presence of bacteria and pulpal inflammation, other potential sources of pulpal injury associated with restorative procedures, include the method of placement of the restorative material $[67,68]$, desiccation [69], chemical irritants $[68,70]$ and restoration material temperature [71,72], as well as the chemical activity of restoration materials [73] and cytotoxicity to pulp tissue [74]. The sensitivity of the odontoblast numbers to different materials was particularly noticeable when the cavity RDT was below $0.5 \mathrm{~mm}$ (Fig. 2), demonstrating the importance of maximising the cavity RDT to reduce possible pulp complications. The type of restorative material also appeared to have an effect on odontoblast numbers, particularly when placed close to the pulp. RMGICs were found to cause the greatest reduction in odontoblast numbers, and we would recommend in agreement with Stanley [75] that calcium hydroxide be applied (dabbed) only to those areas of crown (extensive) preparations before the luting procedure is undertaken, when the RDT is suspected to be less than $0.5 \mathrm{~mm}$. Clearly, decreasing the RDT of cavity restorations can compromise odontoblast survival and influence repair in the pulp-dentine complex after injury. The nature of the restorations can also contribute to these responses. The present extensive study has helped characterise these relationships, and we have schematically illustrated some possible sources of odontoblast injury which may effect dental repair activity in Fig. 5.

\section{Conclusion}

The density of odontoblasts and dental repair activity of the tooth pulp can be correlated to the dimensions of cavity preparation, as well as to etching treatments and the materials used for cavity restoration. Increased awareness of these interactions and attention to reducing possible sources of pulp injury during restorative procedures, such as minimising iatrogenic dentine removal, may prove beneficial to patients.

\section{Acknowledgements}

This work was supported by funds from a short term research program as part of the European COST action B8 on Odontogenesis, and grant No. 057820 from the Wellcome Research Trust Foundation. The authors wish to thank the clinicians of Marseille Hospital Dental Care Centres who prepared the cavities and restorations, mainly Dr J.-L. Brouillet, Dr Y. Miranda and Dr J.-P. Trotebas.

\section{References}

[1] Murray PE, About I, Lumley PJ, et al. Human odontoblast cell numbers after dental injury. Journal of Dentistry 2000;28:277-85.

[2] Linde A. The extracellular matrix of the dental pulp and dentin. Journal of Dental Research 1985;64:523-9.

[3] Baume LJ. Monographs in Oral Science, Basel, Switzerland: Karger, 1980. p. 159-82.

[4] Stanley HR. Human pulp response to restorative dental procedures. Gainsville: Storter Printing Co, 1981.

[5] Cox CF, White KC, Ramus DL, et al. Reparative dentin: 
factors affecting its deposition. Quintessence International 1992;23: $257-70$.

[6] Smith AJ, Tobias RS, Cassidy N, et al. Odontoblast stimulation in ferrets by dentine matrix components. Archives in Oral Biology 1994;39:13-22.

[7] Robertson A, Lundgren T, Andreasen JO, et al. Pulp calcifications in traumatised primary incisors: a morphological and inductive analysis study. European Journal of Oral Science 1997;105:196-206.

[8] About I, Laurent-Maquin D, Lendahl U, et al. Nestin expression in embryonic and adult teeth under normal and pathological conditions. American Journal of Pathology 2000;157:287-95.

[9] Kawasaki K, Tanaka S, Ishikawa T. On the daily incremental lines in human dentine. Archives in Oral Biology 1980;24:939-43.

[10] Morse DR. Age-related changes of the dental pulp complex and their relationship to systemic ageing. Oral Surgery Oral Medicine Oral Pathology 1991;72:721-45.

[11] Solheim T. Amount of secondary dentin as an indicator of age. Scandinavian Journal of Dental Research 1992;100:193-9.

[12] Linde A, Goldberg M. Dentinogenisis. Critical Reviews in Oral Biology Medicine 1993;4:679-728.

[13] Linde A, Lundgren T. From serum to the mineral phase. The role of the odontoblast in calcium transport and mineral formation. International Journal of Developmental Biology 1995;39:213-22.

[14] Smith AJ, Cassidy N, Perry H, et al. Reactionary dentinogenesis. International Journal of Developmental Biology 1995;39:273-80.

[15] Murray PE, About I, Lumley PJ, et al. Postoperative pulpal and repair responses. Journal of the American Dental Association 2000;131:321-9.

[16] Stanley HR, White CL, McCray L. The rate of tertiary (reparative) dentin formation in the human tooth. Oral Surgery Oral Medicine Oral Pathology 1966;21:180-9.

[17] Gwinnett AJ, Tay F. Early or intermediate response of the human pulp to acid etch technique in vivo. American Journal of Dentistry 1998;11:S35-44.

[18] Bergenholtz G. Effect of bacterial products on inflammatory reactions in the dental pulp. Scandanavian Journal of Dental Research 1977;85:122-9.

[19] Chong BS, Pitt Ford TR, Kariyawasam P. Tissue response to potential root-end filling materials in infected root canals. International Endodontic Journal 1997;30:102-14.

[20] Camps J, Déjou J, Rémusat M, et al. Factors influencing pulpal response to cavity restorations. Dental materials 2000;16:432-40.

[21] Sigurdsson A, Stancill R, Madison S. Intracanal placement of $\mathrm{Ca}(\mathrm{OH})_{2}$ : a comparison of techniques. Journal of Endodontics 1992;18:367-70.

[22] Kahn FH, Rosenberg PA, Schertzer L, et al. An in vitro evaluation of sealer placement methods. International Endodontics Journal 1997;30:181-6.

[23] Bránnström M. Communication between the oral cavity and the dental pulp associated with restorative treatment. Operative Dentistry 1984;9:57-68.

[24] Tobias RS, Plant CG, Browne RM. Reduction in pulpal inflammation beneath surface-sealed silicates. International Endodontics Journal 1982;15:173-80.

[25] Sazak S, Günday M, Alatli C. Effect of calcium hydroxide and combinations of ledermix and calcium hydroxide on inflamed pulp in dogs' teeth. Journal of Endodontics 1996;22:447-9.

[26] Kawasaki K, Ruben J, Stokroos I, et al. The remineralization of EDTA-treated human dentine. Caries Research 1999;33:275-80.

[27] Cox CF. Microleakage related to restorative procedures. Proceedings of the Finnish Dental Society 1992;88 (Suppl 1):83-93.

[28] Stewart G, Bachman T, Hatton J. Temperature rise due to finishing of direct restorative materials. American Journal of Dentistry 1991;4:23-28.

[29] Anil N, Keyf F. Temperature change in the pulp chamber during the application of heat to composite and amalgam cores and its returning time to oral heat. International Dental Journal 1996;46:362-6.
[30] Zöllner A, Gaengler P. Pulp reactions to different preparation techniques on teeth exhibiting periodontal disease. Journal of Oral Rehabilitation 2000;27:93-102.

[31] Mjor IA. Biological and clinical properties. In: Mjor IA, editor. Dental materials, biological properties and clinical evaluation, Boca Raton: CRC Press, 1985. p. 91-121.

[32] Mjor IA. Current views on biological testing of restorative materials. J Oral Rehab 1990;17:503-7.

[33] Lille RD, Fulmer HM. Histopathologic technique and practical histochemistry. 4th ed. New York: McGraw-Hill, 1976.

[34] Mjor A. Reaction patterns in human teeth, Boca Raton, FL: CRC Press, 1983. p. 63-156.

[35] Warfvinge J. Morphometric analysis of teeth with inflamed pulp. Journal of Dental Research 1987;66:78-83.

[36] Ramachandra S, Studzinski GP. Morphological and biochemical criteria of apoptosis. Cell growth and apoptosis, New York: Oxford Univ. Press, 1995. p. Ch. 7.

[37] Takahashi K. Microbiological, pathological, inflammatory, immunological and molecular biological aspects of periradicular disease. International Endodontic Journal 1998;31:311-25.

[38] Benjamin N, Cleaton-Jones P, Leidal TI. Histometric evaluation of odontoblast responses to Nobetec and Super-Syntrex. Endodontics and Dental Traumatology 1985;1:180-4.

[39] Stanley HR, Conti AJ, Graham C. Conservation of human research teeth by controlling cavity depth. Oral Surgery 1975;36:151-6.

[40] Darwell BW. Effect of dentine thickness on pulpal changes beneath restorative materials. Australian Dental Journal 1981;26:80-81.

[41] Santini A, Ivanovic V. The quantitation of tertiary dentin formation in response to materials commonly placed in deep cavities in general practice in the UK. Primary Dental Care 1996;3:14-22.

[42] Lee SJ, Walton RE, Osborne JW. Pulp response to bases and cavity depths. American Journal of Dentistry 1992;5:64-68.

[43] Hamid A, Hume WR. The effect of thickness on diffusion of resin monomers in vitro. Journal of Oral Rehabilitation 1997;24:20-25.

[44] Abou Hashieh I, Franquin JC, Cosset A, et al. Relationship between dentine hydraulic conductance and the cytotoxicity of four dentine bonding resins in vitro. Journal of Dentistry 1988;26:473-7.

[45] Zach L. Pulp liability and repair: effect of restorative procedures. Oral Surgery 1972;33:111-21.

[46] Holden GP. Some observations on the vibratory phenomena associated with high-speed air turbines and their transmission to living tissue. British Dental Journal 1962;113:265-75.

[47] Swerdlow H, Stanley HR. Reaction of the human dental pulp to cavity preparation. I. Effect of water spray at $20,000 \mathrm{rpm}$. Journal of the American Dental Association 1958;56:317-29.

[48] Croft L, Stanley HR. The effect of a chilled coolant on the human pulp during cavity preparation. Oral Surgery Oral Medicine Oral Pathology 1966;22:66-71.

[49] Diamond RD, Stanley HR, Swerdlow H. Reparative dentin formation resulting from cavity preparation. Journal of Prosthetic Dentistry 1966;16:1127-34.

[50] Hatton JF, Holtzmann DJ, Ferrillo PJ, et al. Effect of handpiece pressure and speed on intrapulpal temperature rise. American Journal of Dental Research 1994;7:108-10.

[51] Ottl P, Lauer H-C. Temperature response in the pulp chamber during ultrahigh-speed tooth preparation with diamond burs on different grit. Journal of Prosthetic Dentistry 1998;80:12-19.

[52] Santini A, Mitchell S. A scanning electron microscopic study of the effect of Gluma CPS bonding system on dentinal smear layers produced by different bur types and rotational speeds and on the resin-dentin interface. Quintessence International 1998;29: $737-47$.

[53] Ohmoto K, Taira M, Shintani H, et al. Studies on dental high-speed cutting with carbide burs used on bovine dentin. Journal of Prosthetic Dentistry 1996;71:319-23.

[54] Liao WM, Taira M, Ohmoto K, et al. Studies on high speed cutting. Journal of Oral Rehabilitation 1995;22:67-72. 
[55] Brisman DL. The effect of speed, pressure, and time on bone temperature during the drilling of implant sites. International Journal of Oral Maxillofacial Implants 1996;11:35-37.

[56] Ohmoto K, Taira M, Shintani H, Yamaki M. Studies on dental highspeed cutting with carbide burs used on bovine dentine. Journal of Prosthetic Dentistry 1994;71:319-23.

[57] Lloyd BA, Rich JA, Brown WS. Effect of cooling techniques on temperature control and cutting rate for high-speed dental drills. Journal of Dental Research 1978;57:675-84.

[58] Mahon WT, Hembree JH, Yates JL, et al. The influence of ultra speed cutting instruments and coolants on in vitro intrapulpal temperature changes during cavity preparation. Journal of the Tennessee Dental Association 1981;61:13-17.

[59] Dachi SF, Stigers RW. Pulpal effects of water and air coolants used in high-speed cavity preparations. Journal of the American Dental Association 1968;76:95-98.

[60] Pameijer CH, Stanley HR. Pulp reaction to a dentin bonding agent. American Journal of Dentistry 1995;8:140-4.

[61] Torstenson B, Nordenvall KJ, Brannstrom M. Pulpal reaction and micro-organisms under clearfil composite resin in deep cavities with acid etched dentin. Swedish Dental Journal 1982;6:167-76.

[62] Tao L, Tagami J, Pashley DH. Effects of pulpal pressure on bond strengths of Superbond and Gluma. American Journal of Dentistry 1991;4:73-76.

[63] Bergenholtz G. Effect of bacterial products on inflammatory reactions in the dental pulp. Scandinavian Journal of Dental Research 1977;85:122-9.

[64] Bergenholtz G, Cox CF, Loesche WJ, Syed SA. Bacterial microleak age around dental restorations: its effect on the dental pulp. Journal of Oral Pathology 1982;11:439-50.
[65] Pashley DH. Clinical considerations of microleakage. Journal of Endodontics 1990;16:70-77.

[66] Lindemann RA, Hume WR, Wolcott RB. Dentin permeability and pulpal response to EDTA. Journal of Prosthetic Dentistry 1985; 53:341-3.

[67] Sigurdsson A, Stancill R, Madison S. Intracanal placement of $\mathrm{Ca}(\mathrm{OH})_{2}$ : a comparison of techniques. Journal of endodontics 1992;18:367-70.

[68] Kahn FH, Rosenberg PA, Schertzer L, et al. An in vitro evaluation of sealer placement methods. International Endodontics Journal 1997; 30:181-6.

[69] Bránnström M. Communication between the oral cavity and the dental pulp associated with restorative treatment. Operative Dentistry 1984;9:57-68.

[70] Kawasaki K, Ruben J, Stokroos I, et al. The remineralization of EDTA-treated human dentine. Caries Research 1999;33:275-80.

[71] Stewart G, Bachman T, Hatton J. Temperature rise due to finishing of direct restorative materials. American Journal of Dentistry 1991;4:23-28.

[72] Anil N, Keyf F. Temperature change in the pulp chamber during the application of heat to composite and amalgam cores and its returning time to oral heat. International Dental Journal 1996;46:362-6.

[73] Murray PE, Lumley PJ, Smith AJ, Ross HF. The influence of sample dimensions on hydroxyl ion release from calcium hydroxide products. Endodontics and Dental Traumatology 2000;16:251-57.

[74] Murray PE, Lumley PJ, Ross HF, Smith AJ. Tooth slice organ culture for cytotoxicity assessment of dental materials. Biomaterials 2000;21:1711-21.

[75] Stanley HR. Pulpal considerations of adhesive materials. Operative Dentistry 1992;5:151-64. 